\title{
Effects of IGF-1 on IL-1 $\beta$-induced apoptosis in rabbit nucleus pulposus cells in vitro
}

\author{
CHANG-CHUN ZHANG ${ }^{1,2}$, JIAN-SHENG ZHOU ${ }^{1,2}$, JIAN-GUO HU ${ }^{2}$, XIANG WANG ${ }^{3}$,

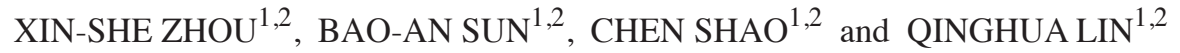 \\ ${ }^{1}$ Department of Orthopedics, The First Affiliated Hospital of Bengbu Medical College \\ ${ }^{2}$ Anhui Key Laboratory of Tissue Transplantation, Bengbu Medical College, Bengbu 233004; \\ ${ }^{3}$ Department of Orthopedics, The First Affiliated Hospital, Zhejiang University \\ School of Medicine, Hangzhou 310058, P.R. China
}

Received September 18, 2012; Accepted November 30, 2012

DOI: $10.3892 / \mathrm{mmr} .2012 .1238$

\begin{abstract}
Excessive apoptosis in intervertebral disc (IVD) cells is important in IVD degeneration. Interleukin (IL)- $1 \beta$ has been shown to induce apoptosis in these cells. However, whether insulin-like growth factor-1 (IGF-1) inhibits IL-1 $\beta$ induced apoptosis in the nucleus pulposus remains unclear. The purpose of this study was to investigate the effects of IGF-1 on IL-1 $\beta$-induced apoptosis in the nucleus pulposus. Cells isolated from the nucleus pulposus were grown in culture to a monolayer. These cells were identified using immunohistochemistry for type II collagen and toluidine blue staining for glycosaminoglycans. Following exposure to IGF-1 or IL-1 $\beta$, the cells were observed using light microscopy. Giemsa staining, TdT-mediated dUTP-biotin nick end-labeling (TUNEL) and flow cytometry (FCM) were used to detect the rate of early cell death, which served as an indicator of apoptosis. In the IL- $1 \beta$ group, a large number of these cells underwent apoptosis and demonstrated morphological changes associated with apoptosis. A small proportion of cells exposed to IGF-1 alone underwent apoptosis. No obvious signs of apoptosis were observed in the control group. TUNEL results revealed that the rate of apoptosis in the IGF-1 group was significantly reduced compared with that in the IL-1 $\beta$ group $(\mathrm{P}<0.01)$, confirmed using FCM. Compared with the control group, the apoptotic rate was also significantly increased in IL-1 $\beta$-exposed cells $(\mathrm{P}<0.01)$. These findings strongly suggested that IGF-1 inhibits IL-1 $\beta$-induced apoptosis in the nucleus pulposus.
\end{abstract}

Correspondence to: Professor Jian-Sheng Zhou, Department of Orthopedics, The First Affiliated Hospital of Bengbu Medical College, 287 Chang Huai Road, Bengbu 233004, P.R. China

E-mail: cczhang01@yahoo.com.cn

Key words: intervertebral disc degeneration, nucleus pulposus, apoptosis, insulin-like growth factor-I, interleukin-1 $\beta$, insulin-like growth factor-1

\section{Introduction}

Intervertebral disc (IVD) degeneration is a common clinical problem that may result in low back pain and physical disability. Progressive loss of proteoglycans and disc dehydration, the major pathological characteristics of disc degeneration, may lead to alterations in disc structure and impaired disc function. The outer third of the IVD consists of the annulus fibrosus and nucleus pulposus. The latter is rich in proteoglycans, which are necessary for the normal function of the IVD. Recent findings have demonstrated that the number of nucleus pulposus cells is reduced and the composition of the extracellular matrix (ECM) associated with these cells is altered in degenerated discs (1-3).

Interleukin (IL)-1, a proinflammatory cytokine present in the degenerating disc (4-6), is thought to contribute significantly to the loss of ECM integrity and nucleus pulposus cells (3). Only one cell line is present in the nucleus pulposus, and its constituents are responsible for secreting the content of the ECM. Therefore, the ability of IL-1 $\beta$ to reduce the number of cells in the nucleus pulposus and, thus, alter the characteristics of the ECM, may be important in the degeneration of the disc. Growth factors such as tumor growth factor (TGF)- $\beta 1$ and insulin-like growth factor (IGF)-1 have been shown to stimulate the proliferation of nucleus pulposus cells in humans $(7,8)$. Findings of previous studies suggested that growth factors also induce the regeneration of normal ECM in the IVD $(9,10)$.

To determine whether there is a therapeutic role for growth factors in individuals with disc degeneration, we investigated the effects of IGF-1 on the IL- $1 \beta$-induced loss of nucleus pulposus cells using light microscopy, Giemsa staining, TdT-mediated dUTP-biotin nick end-labeling (TUNEL) and flow cytometry (FCM).

\section{Materials and methods}

Cell culture. IVDs were obtained from lumbar spines of mature New Zealand white rabbits immediately postmortem. The nucleus pulposus was harvested from these specimens, washed with Hank's balanced salt solution (HBSS), and transported to the laboratory within $30 \mathrm{~min}$ of harvesting. The nucleus 
pulposus tissue was rinsed 3 times in HBSS and then dissected into small fragments $\sim 1 \mathrm{~mm}^{3}$ in size. Cells were isolated from the nucleus pulposus using sequential enzyme digestion with $0.25 \%$ trypsin for $30 \mathrm{~min}$, washed with HBSS and incubated in $0.1 \%$ collagenase type II at $37^{\circ} \mathrm{C}$ for $2-3 \mathrm{~h}$. The cells were collected by filtering through a 200 -mesh nylon cell strainer and subjected to centrifugation of $1,000 \mathrm{x}$ g for $5 \mathrm{~min}$. The cells were then washed twice with phosphate-buffered saline, resuspended and grown in medium containing Dulbecco's modified Eagle's medium with Ham's F-12 nutrient mixture (DMEM-F12) supplemented with 10\% (vol/vol) fetal bovine serum (FBS) plus $1 \%$ penicillin and streptomycin. The culture medium was changed every 2-3 days. The phenotype of the nucleus pulposus cell was confirmed using positive immunostaining for type II collagen and toluidine blue staining of glycosaminoglycans. First-passage chondrocytes were used in our experiments.

Cells were grown in $80 \%$ confluency, first-passage chondrocytes were digested using trypsin and then transferred to 6-well plates to grow to a density of $1 \times 10^{5} / \mathrm{ml}$ in DMEM-F12 supplemented with $10 \%$ (vol/vol) FBS. After $24 \mathrm{~h}$ of adherence, the medium was changed to DMEM-F12 without FBS, and the cells were cultured for another $24 \mathrm{~h}$. At that time, the medium was removed, and the cells were grown in DMEM-F12 containing IL-1 $\beta(100 \mu \mathrm{g} / \mathrm{l})$ with or without IGF-1 (500 $\mu \mathrm{g} / \mathrm{l})$ for $24 \mathrm{~h}$. A subset of cells grown in DMEM-F12 without FBS for $24 \mathrm{~h}$ served as controls.

Animal care was carried out in accordance with the National Institute of Health Guide for the Care and Use of Laboratory Animals (NIH Publications no. 80-23; revised 1996) and was approved by the Bengbu Medical College Animal Care Committee of the Use of Laboratory Animals.

Giemsa staining. The cells were digested using trypsin and cultured in 6-well plates, each of which contained a $1 \times 1-\mathrm{cm}$ cover glass. The slides were removed $12 \mathrm{~h}$ later. The cells growing on each slide were fixed in methanol for $2 \mathrm{~min}$. Giemsa staining solution was then applied for $10 \mathrm{~min}$, and the cells were made transparent using xylene. The cells were then covered and observed using light microscopy.

TUNEL assay. The cells were again subjected to trypsinization and cultured in 6-well plates, each containing a $1 \times 1-\mathrm{cm}$ cover glass. The glass slides were removed $12 \mathrm{~h}$ later, and the cells growing on them were fixed in $4 \%$ paraformaldehyde for 60 min. Methanol containing 3\% $\mathrm{H}_{2} \mathrm{O}_{2}$ was then applied for $5 \mathrm{~min}$ to inactivate endogenous peroxidase. The cells were then exposed to $0.1 \%$ Triton $\mathrm{X}-100$ at $4^{\circ} \mathrm{C}$ for $2 \mathrm{~min}$, incubated with $50 \mu \mathrm{l}$ of the TUNEL reaction mixture ( $5 \mu \mathrm{l}$ TdT-enzyme solution $+45 \mu$ l of nucleotide mixture solution) in the dark at $37^{\circ} \mathrm{C}$ for $60 \mathrm{~min}$, exposed to 3,3'-diaminobenzidine (DAB), and then counterstained with hematoxylin. The cells were then dehydrated using graded ethanol and covered with a xylene-based mounting medium. The percentage of TUNELpositive cells from the control, IL- $1 \beta$ and L-1 $\beta^{+}$IGF-1 groups were determined by counting the TUNEL-positive cells under 10 non-continuous low-power fields (magnification, x100).

Flow cytometry. Cells were cultured in DMEM-F12 containing IL-1 $\beta 100 \mu \mathrm{g} / \mathrm{l}$ with or without IGF-1 $500 \mu \mathrm{g} / \mathrm{l}$ for $24 \mathrm{~h}$. Cells
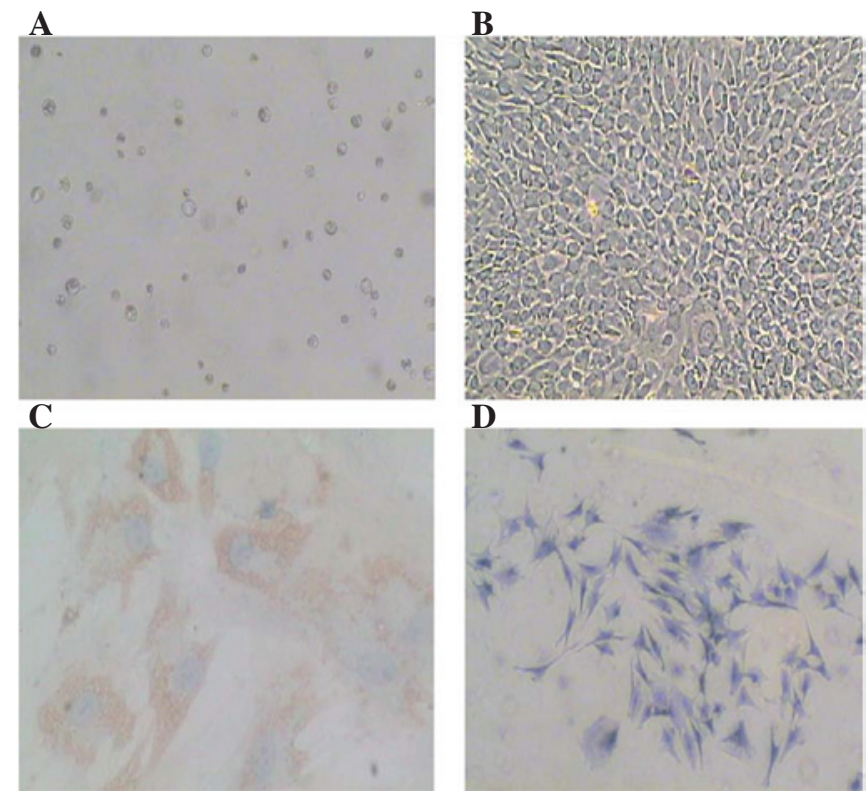

Figure 1. Isolation, culture and identification of primary nucleus pulposus cells. (A) Primary nucleus pulposus cells were obtained using sequential enzyme digestion (magnification, x40). (B) Pulposus cells formed a complete monolayer after being cultured for 7-10 days (magnification, x100). (C) Immunostaining revealed that these cells are positive for type II collagen, a marker of the nucleus pulposus cell (magnification, x200). (D) Toluidine blue staining demonstrated that these cells are positive for proteoglycans (magnification, x100).

cultured in DMEM-F12 without FBS for $24 \mathrm{~h}$ served as controls. The cells were then digested using trypsin, collected, washed in FCM buffer, and resuspended in FCM wash buffer. To detect cell apoptosis, the cells were incubated with $5 \mu \mathrm{l}$ of Annexin V-FITC incubation reagent in the dark for $15 \mathrm{~min}$ at $4^{\circ} \mathrm{C}$, followed by incubation with propidium iodine (PI)-PE of $10 \mu \mathrm{l}$ for $5 \mathrm{~min}$ at $4^{\circ} \mathrm{C}$. Samples were analyzed within $30 \mathrm{~min}$ using FCM.

Statistical analysis. Data were presented as the means \pm SD $(\mathrm{n}=3)$. Groups of data were compared statistically using the Mann-Whitney U test. Values were considered statistically significant when $\mathrm{P}<0.05$.

\section{Results}

Cultivation and identification of the nucleus pulposus cells. Primary nucleus pulposus cells were obtained by sequential enzyme digestion and cultured in DMEM-F12 10\% FBS (Fig. 1A). Following culture for 7-10 days, the cells formed a complete monolayer (Fig. 1B). To identify the nucleus pulposus phenotype cell, toluidine blue staining was used to identify glycosaminoglycans and immunostaining was used to detect type II collagen (Fig. 1C and D). The results showed that these cells expressed both type II collagen and glycosaminoglycans, thus demonstrating the phenotype of nucleus pulposus cells.

IL-1 $\beta$-induced apoptosis of nucleus pulposus cells. The result obtained from Giemsa staining indicates that nuclear fragmentation occurred following culture of nucleus pulposus cells in the presence of $100 \mu \mathrm{g} / 1 \mathrm{IL}-1 \beta$ (Fig. 2), suggesting that IL-1 $\beta$ 


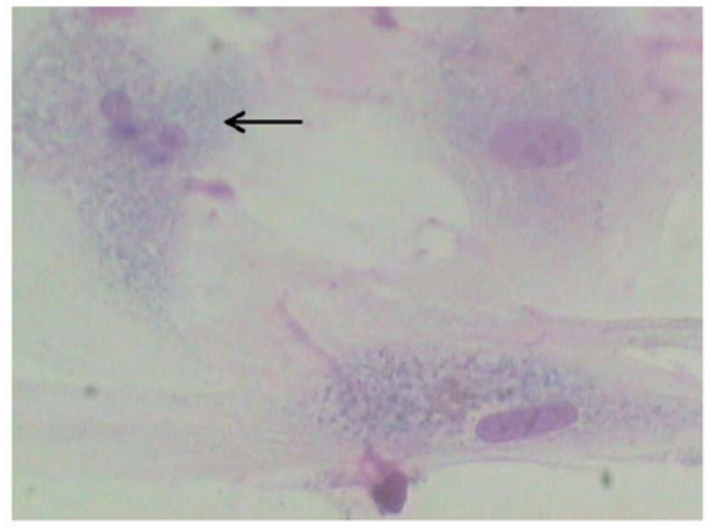

Figure 2. Giemsa staining after incubation in IL-1 $(100 \mu \mathrm{g} / \mathrm{l})$ for $24 \mathrm{~h}$ reveals nuclear fragmentation in the nucleus pulposus cells. (magnification, x200).
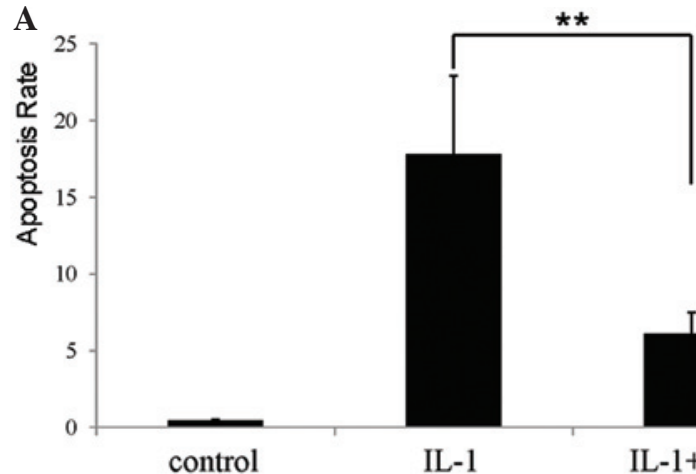

B

control

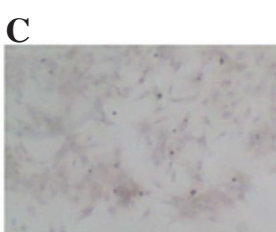

IL-1

D

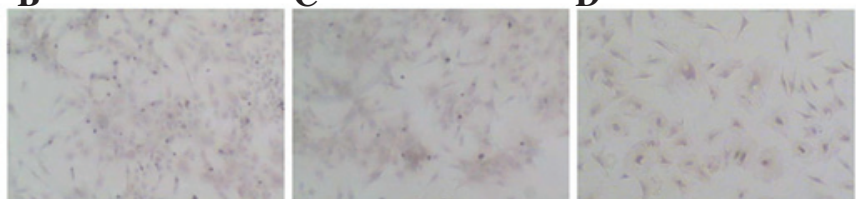

Figure 3. (A) TUNEL assay indicated the apoptosis of the primary nucleus pulposus cells. The percentage of TUNEL-positive cells was markedly greater in (B) the IL-1 $\beta$-treated group compared with (C) the controls. (D) However, IL-1 $\beta$-induced apoptosis was significantly suppressed $(\mathrm{P}<0.01)$ by IGF-1.

induced apoptosis of nucleus pulposus cells. TUNEL staining also showed that the percentage of TUNEL-positive cells was markedly greater in the IL-1 $\beta$-treated group than that in the controls (Fig. 3A-C).

IGF-1 reduced IL-1 $\beta$-induced apoptosis of nucleus pulposus cells. To determine whether IGF-1 affected IL-1 $\beta$-induced apoptosis of nucleus pulposus cells, both $500 \mu \mathrm{g} / 1$ IGF-1 and $100 \mu \mathrm{g} / 1 \mathrm{IL}-1 \beta$ were added into culture medium simultaneously. The result of TUNEL indicated that IL-1 $\beta$-induced apoptosis was significantly suppressed $(\mathrm{P}<0.01)$ in the presence of IGF-1 (Fig. 3A and D), suggesting that IGF-1 inhibits apoptosis of nucleus pulposus cells induced by IL-1 $\beta$.

The results of TUNEL were confirmed by FCM. The percentage of nucleus pulposus cells with signs of early and late stages of apoptosis was significantly higher in the IL-1 $\beta$ group compared with the controls. However, the treatment of IGF-1 reduced IL-1 $\beta$-induced apoptosis of nucleus pulposus cells (Fig. 4A-C, $\mathrm{P}<0.01$ ).
A

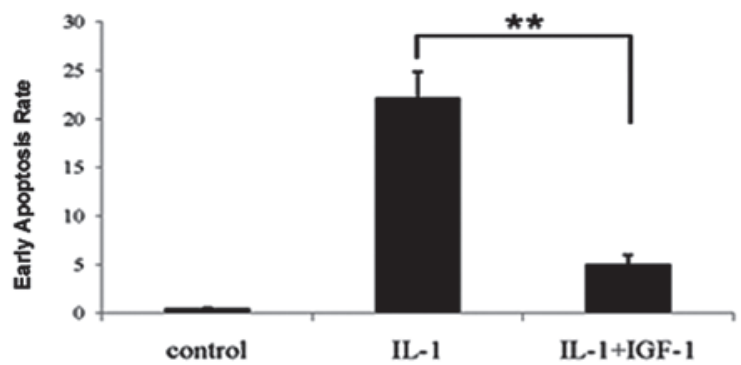

B

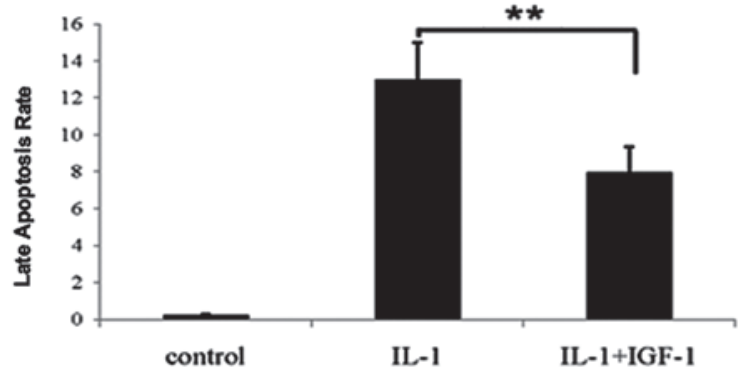

C

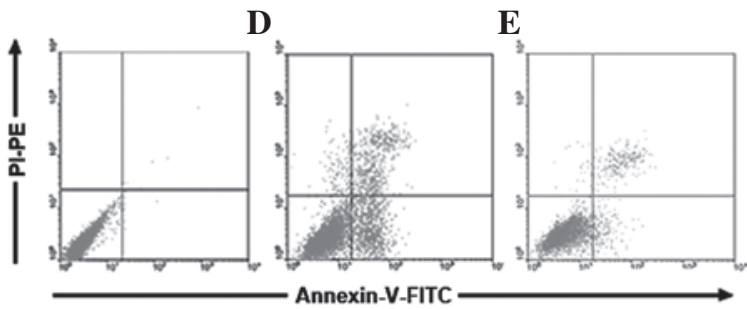

Figure 4. Results of flow cytometry indicated the apoptosis of the primary nucleus pulposus cells. The percentage of nucleus pulposus cells with signs of (A) early and (B) late stage of apoptosis was significantly higher in the IL-1 $\beta$ group compared with the controls. However, the treatment of IGF-1 reduced IL-1 $\beta$-induced apoptosis of nucleus pulposus cells. Representative photomicrographs show patterns of the early or late stage of apoptosis Annexin V/PI-postive cells in the (D) IL-1 $\beta$, (E) IL-1 $\beta+$ IGF-1 and (C) control groups.

\section{Discussion}

Proinflammatory cytokines including IL-1 $\beta$, IL-6, prostaglandin E2 and TNF are important in the mechanism underlying IVD (11-13). These cytokines are able to induce the production of factors associated with inflammation, pain and disc matrix catabolism in the nucleus pulposus (14). IL-1 $\beta$ upregulates the expression of $M M P-3$ and $M M P-9$, which may contribute to the catabolism of the disc matrix (12), thereby playing an important role in the pathological degradation of the disc. Moreover, investigators found a simultaneous reduction in matrix synthesis factors (aggrecan, type II collagen, and Sox9) and an increase in inflammatory cytokine (IL-1 $\beta$ and TNF) levels during disc degeneration (15). These observations indicate that proinflammatory cytokines stimulate the degradation of the ECM surrounding the nucleus pulposis, which may lead to disc degeneration.

The late stage of disc degeneration is characterized by a reduction in the number of nucleus pulposis cells, and IL-1 $\beta$ is thought to contribute significantly to this loss. Thus, IL-1 $\beta$-induced nucleus pulposus cell apoptosis may also be involved in disc degeneration. Our findings have shown that IL-1 $\beta$ was able to induce apoptosis of nucleus pulposus cells. It has been proven that IGF-1 is efficient in stimulating the 
proliferation of human nucleus pulposus cells $(9,16)$. Results of a recent study have indicated that exogenous and autocrine growth factors such as platelet-derived growth factor, basic fibroblast growth factor, and IGF-I stimulate the proliferation of human IVD through the MEK/ERK and PI-3K/Akt pathways (8). Findings of an in vivo study indicated that age-related disc degeneration is associated with downregulation of the expression of IGF-1 (17), while findings of an in vitro study demonstrated that IGF-1-dependent proteoglycan synthesis decreased with age (9). Taken together, these results suggest that IGF-1 likely contributes to the development of clinical interventions for disc degeneration. In the present study, the results from TUNEL and FCM indicated that the rate of apoptosis is particularly high in nucleus pulposus cells in the presence of IL-1 $\beta$ compared with the controls. However, when treated with IGF-1, the apoptosis of nucleus pulposus cells induced by IL-1 $\beta$ was reduced significantly, suggesting that IGF-1 reverses IL-1 $\beta$-induced apoptosis of nucleus pulposus cells in vitro. The results from FCM also suggest that IL-1 $\beta$ induced both the early and late stages of apoptosis of nucleus pulposus cells and that the apoptosis was suppressed by IGF-1. These results were similar to those of a study suggesting that anabolic cytokines such as TGF and IGF-1 likely have a fundamental role in the prevention of degenerative disc disease $(18,19)$, maintainance of ECM synthesis, and prevention of disc degeneration.

In conclusion, findings of this study have demonstrated that IGF-1 reverses IL-1 $\beta$-induced apoptosis of nucleus pulposus cells. Thus, IGF-1 is a potentially appropriate target for the development of treatments for individuals with disc degenerative disease.

\section{Acknowledgements}

This study was supported by the Key Research Foundation of the Education Bureau of Anhui Province, China (KJ2011A204).

\section{References}

1. Freemont AJ: The cellular pathobiology of the degenerate intervertebral disc and discogenic back pain. Rheumatology (Oxford) 48: 5-10, 2009.

2. Smith LJ, Nerurkar NL, Choi KS, et al: Degeneration and regeneration of the intervertebral disc: lessons from development. Dis Model Mech 4: 31-41, 2011.

3. Le Maitre CL, Freemont AJ and Hoyland JA: The role of interleukin-1 in the pathogenesis of human intervertebral disc degeneration. Arthritis Res Ther 7: R732-R745, 2005.

4. Le Maitre CL, Freemont AJ and Hoyland JA: A preliminary in vitro study into the use of IL-1Ra gene therapy for the inhibition of intervertebral disc degeneration. Int J Exp Pathol 87: $17-28,2006$
5. Smith LJ, Chiaro JA, Nerurkar NL, et al: Nucleus pulposus cells synthesize a functional extracellular matrix and respond to inflammatory cytokine challenge following long-term agarose culture. Eur Cell Mater 22: 291-301, 2011.

6. Studer RK, Vo N, Sowa G, et al: Human nucleus pulposus cells react to IL-6: independent actions and amplification of response to IL-1 and TNF- $\alpha$. Spine (Phila Pa 1976) 36: 593-599, 2011.

7. Zhang R, Ruan D and Zhang C: Effects of TGF-beta1 and IGF-1 on proliferation of human nucleus pulposus cells in medium with different serum concentrations. J Orthop Surg Res 1: 9, 2006.

8. Pratsinis H, Constantinou V, Pavlakis K, et al: Exogenous and autocrine growth factors stimulate human intervertebral disc cell proliferation via the ERK and Akt pathways. J Orthop Res 30: 958-964, 2012.

9. Okuda S, Myoui A, Ariga K, et al: Mechanisms of age-related decline in insulin-like growth factor-I dependent proteoglycan synthesis in rat intervertebral disc cells. Spine (Phila Pa 1976) 26: 2421-2426, 2001.

10. Osada $\mathrm{R}$, Ohshima $\mathrm{H}$, Ishihara $\mathrm{H}$, et al: Autocrine/paracrine mechanism of insulin-like growth factor-1 secretion, and the effect of insulin-like growth factor-1 on proteoglycan synthesis in bovine intervertebral discs. J Orthop Res 14: 690-699, 1996.

11. Erwin WM, Islam D, Inman RD, et al: Notochordal cells protect nucleus pulposus cells from degradation and apoptosis: implications for the mechanisms of intervertebral disc degeneration. Arthritis Res Ther 13: R215, 2011.

12. Millward-Sadler SJ, Costello PW, Freemont AJ and Hoyland JA: Regulation of catabolic gene expression in normal and degenerate human intervertebral disc cells: implications for the pathogenesis of intervertebral disc degeneration. Arthritis Res Ther 11: R65, 2009.

13. Park JY, Kuh SU, Park HS and Kim KS: Comparative expression of matrix-associated genes and inflammatory cytokines-associated genes according to disc degeneration: analysis of living human nucleus pulposus. J Spinal Disord Tech 24: 352-357, 2011.

14. Studer RK, Aboka AM, Gilbertson LG, et al: p38 MAPK inhibition in nucleus pulposus cells: a potential target for treating intervertebral disc degeneration. Spine (Phila Pa 1976) 32: 2827-2833, 2007.

15. Zhang Y, An HS, Toofanfard M, et al: Low-dose interleukin-1 partially counteracts osteogenic protein-1-induced proteoglycan synthesis by adult bovine intervertebral disk cells. Am J Phys Med Rehabil 84: 322-329, 2005.

16. Mavrogonatou E and Kletsas D: Effect of varying osmotic conditions on the response of bovine nucleus pulposus cells to growth factors and the activation of the ERK and Akt pathways. J Orthop Res 28: 1276-1282, 2010.

17. Murakami H, Yoon ST, Attallah-Wasif ES, et al: The expression of anabolic cytokines in intervertebral discs in age-related degeneration. Spine (Phila Pa 1976) 31: 1770-1774, 2006.

18. Okuda S, Myoui A, Ariga K, et al: Mechanisms of age-related decline in insulin-like growth factor-I dependent proteoglycan synthesis in rat intervertebral disc cells. Spine (Phila Pa 1976) 26: 2421-2426, 2001.

19. Le Maitre CL, Richardson SM, Baird P, et al: Expression of receptors for putative anabolic growth factors in human intervertebral disc: implications for repair and regeneration of the disc. J Pathol 207: 445-452, 2005.

20. Jiang F, Frederick TJ and Wood TL: IGF-I synergizes with FGF-2 to stimulate oligodendrocyte progenitor entry into the cell cycle. Dev Biol 232: 414-423, 2001. 